\title{
Antimicrobial Effects of Camel Milk against Some Bacterial Pathogens
}

\author{
Magdy Hassan YASSIN ${ }^{1,2, *}$, Mahamed Mohamed Soliman ${ }^{3,4}$, Salama Abd-Elhafez Mostafa ${ }^{1,5}$, \\ Hussein Abdel-Maksoud $\mathrm{Ali}^{4}$ \\ ${ }^{1}$ Department of Medical Microbiology, Faculty of Applied Medical Sciences, Turabah, Taif University, Saudi Arabia \\ ${ }^{2}$ Reproductive diseases Department, Animal Reproduction Research Institute, Al-Haram, Egypt \\ ${ }^{3}$ Medical Laboratory Department, Faculty of Applied Medical Sciences, Turabah, Taif University, Saudi Arabia \\ ${ }^{4}$ Department of Biochemistry, Faculty of Veterinary Medicine, Benha University, Egypt \\ ${ }^{5}$ Immunopharmacology Unit, Animal Reproduction Research Institute, Al-Haram, Egypt \\ *Corresponding author: magdymyh@gmail.com
}

Received February 01, 2015; Revised February 22, 2015; Accepted March 03, 2015

\begin{abstract}
The present study was aimed to investigate the protective effects of camel milk against pathogenicity induced by Staphylococcus aureus (S. aureus) and E. coli in Wistar rats. Sixty healthy adult male Wistar rats were divided into six groups (10 per group). Group 1 served as a control without any treatment. Group 2 received camel milk for two consecutive weeks. Group 3 injected intraperitoneally (IP) by S. aureus in a doses of $2 \times 10^{9} \mathrm{CFU} / \mathrm{ml}$ per rat. Group 4 injected IP by E.coli in a dose of $5 \times 10^{10} \mathrm{CFU} / \mathrm{ml}$ per rat. Group 5 supplemented with camel milk for two consecutive weeks and then injected IP by S.aureus ( $2 \times 10^{9} \mathrm{CFU} / \mathrm{ml}$ per rat). Group 6 supplemented with camel milk for two consecutive weeks and then injected IP by E.coli $\left(5 \times 10^{10} \mathrm{CFU} / \mathrm{ml}\right.$ per rat). All animals were decapitated after 3 weeks, serum was extracted and liver, kidney and lung tissues were taken for pathogen isolation. The isolation rate and pathogenicity of $S$. aureus and $E$. coli was high in rats injected pathogens alone (group 3 and 4) compared to camel milk and pathogens administered rats (group 5 and 6). The isolation of S. aureus and E. coli was high in intestine, then lung, kidney and liver. Prior camel milk supplementation ameliorated the degree of pathogenicity induced by pathogens. Camel milk had synergistic action with ciprofloxacin against $S$. aureus and $E$. coli to reduce bacterial resistance and decrease the dose of antibiotics. Pathogens injection alone induced significant amelioration in liver and kidney functions and prior camel milk administration inhibited such changes. Moreover, oxidative stress represented by the increase in malondialdehyde levels in serum of pathogens injected rats was decreased by prior camel milk administration. In conclusion, camel milk has beneficial role as antibacterial food supplement against S.aureus and E.coli pathogenicity in Wistar rats.
\end{abstract}

Keywords: camel milk supplementation, antibacterial activity, E. coli and S. aureus pathogenicity, wistar rats

Cite This Article: Magdy Hassan YASSIN, Mahamed Mohamed Soliman, Salama Abd-Elhafez Mostafa, and Hussein Abdel-Maksoud Ali, “Antimicrobial Effects of Camel Milk against Some Bacterial Pathogens.” Journal of Food and Nutrition Research, vol. 3, no. 3 (2015): 162-168. doi: 10.12691/jfnr-3-3-6.

\section{Introduction}

Camels play a major role in the lifestyle of many communities, particularly those in dry zones in the Middle East and the Arabian area. Camels have the ability to adapt to climatic conditions. They are used in transport, sport, source of meat and milk Therefore, camels, contribute in raising the economy and food security for humans. It has been found that camel milk has antidiabetic, anti-hepatitis and bactericidal [1,2,3].The milk of mammals is protected to different extents against microbial contaminations by natural inhibitory systems, including the lactoperoxidase/ thiocyanate/hydrogen peroxide system, lactoferrins, lysozyme, immunoglobulins and free fatty acids [3]. The concentration and the activity of each of these antimicrobial systems/substances depend on the animal species and on the stage of lactation.
Camel's milk is reported to have a stronger inhibitory system than that of cow's milk [1]. In particular; the levels of lysozyme and lactoferrins are reported to be two and three times higher than those of cow's milk, respectively $[4,5]$. Camel milk contains peptides and proteins that exhibit its biological activities that have beneficial effect on many bioprocesses as digestion, absorption, growth and immunity [6,7]. Furthermore, camel's milk can be stored at room temperature longer period than milk from other animals [8]. Camel's whey proteins include a heterogeneous group of proteins, including serum albumin, $\alpha$-lactalbumin, immunoglobulin, lactophorin and peptidoglycan recognition protein [9]. Dietary whey supplementations may improve wound healing by increasing GSH synthesis and cellular antioxidant defense [10].

S. aureus microorganism is responsible for many infections but it may occurs as a commensal. The presence of $S$. aureus does not always indicate infection. S.aureus 
can survive from hours to weeks, or even months, on dry environmental surfaces, depending on strain [11]. $S$. aureus infections can spread through contact with pus from an infected wound, skin-to-skin contact with an infected person by producing hyaluronidase that destroys tissues, and contact with objects such as towels, sheets, clothing, or athletic equipments used by an infected person. Deeply penetrating S.aureus infections can be severe. Sever S. aureus infection causes septic arthritis, endocarditis and pneumonia and mastitis in animals [11]. On the other hand, Escherichia coli (E.coli) are Gram negative bacilli (Enterobacteriaceae) founds in the intestinal tract as a commensal. Pathogenic strains of this organism are distinguished from normal flora by their possession of virulence factors such as exotoxins. The specific virulence factors can be used, together with the type of disease, to separate these organisms into pathotypes. There are two major families of verocytotoxins, Vt1 and Vt2. Enterohemorrhagic E. coli are VTEC that possess additional virulence factors, giving them the ability to cause hemorrhagic colitis and hemolytic uremic syndrome in humans [12]. From the above stated facts about the importance of camel milk and severity of S. aureus and E. coli comes the importance of this study. Therefore, current study aimed to investigate the protective effect of camel milk on the pathogenicity induced by $E$. coli and S. aureus injection in Wistar rats

\section{Materials and Methods}

\subsection{Bacterial Strain Preparation}

The used bacterial clinical isolate, S. aureus (MRSA) strain and Enterohaemorrhagic strain of E. coli were kindly provided from the Department of Udder and Neonates (Animal Reproduction Research Institute AlHaram, Egypt).

The bacterial culture of $S$. aureus was grown in tryptic broth and incubated over night. The bacterial culture was then centrifuged at $15,000 \times g$ for $15 \mathrm{~min}$ and the pellet was resuspended and washed with sterile phosphate buffer saline (PBS). The viable bacterial count was adjusted to approximately $2 \times 10^{9}$ colony forming units (CFU)/mL.

E. coli (Enterohaemorragic) strain was grown in brain heart infusion broth. When bacteria were in the log phase of growth, the suspension was centrifuged at 15,000 $\mathrm{xg}$ for $15 \mathrm{~min}$, the supernatant was discarded, and the bacteria were re-suspended and diluted into sterile saline. The viable bacterial count was adjusted to approximately $5 \mathrm{X}$ $10^{10} \mathrm{CFU} / \mathrm{mL}$.

\subsection{Examination the in vitro Synergistic Action of Camel Milk and Antibiotics}

Standard well agar diffusion method was carried out to detect the antibacterial activity of camel milk and the synergistic action of camel milk and antibiotics against pathogenic organisms (S. aureus and E. coli). Based on protocol stated by Cheesbrough, [13], pure cultures of organism were swabbed uniformly on the individual plates using sterile cotton swab. Wells of size $6 \mathrm{~mm}$ have been made in Muller-Hinton agar plates using gel puncture. Using micropipette, $100 \mu \mathrm{l}$ of the camel milk were poured into wells on all plates .Antibiotic ciprofloxacin $(5 \mathrm{mcg}$ ) discs were placed on the well of camel milk and alone in Muller-Hinton agar. After incubation at $37{ }^{\circ} \mathrm{C}$ for $24 \mathrm{~h}$, the different levels of zone of inhibition were measured.

\subsection{Camel's Milk Preparation}

Camel's milk samples were collected daily early in the morning from camel farm in Turabah, Taif, Saudi Arabia. Milk was collected from healthy camel (4 years old) by hand milking in sterile screw bottles and kept in cool boxes until transported to the laboratory. Rats were supplemented with unpasteurized camel milk.

\subsection{Experimental Animals and Design}

Male Wistar rats (60 rats), 3 months old, weighting 200-250 g, were selected randomly. Rats were exposed to $12 \mathrm{~h} / 12 \mathrm{~h}$ day light with free access to food and water. The sixty rats were divided into six groups (10 rats per group). Control group was fed normal diet, camel milk group was supplemented in a dose of $100 \mathrm{ml}$ per 6 rats based on a reported study [14]. E. coli group was injected intraperitoneally (IP) virulent strain of $E$ coli in a dose of $2 \times 10^{10} \mathrm{CFU} / \mathrm{ml}$ per rat [15], E. coli plus camel milk group, $S$. aureus group was injected IP with a virulent strain of $S$. aureus in a dose of $2 \times 10^{9} \mathrm{CFU} / \mathrm{mL}$ per rats [16] and $S$. aureus plus camel milk group. Rats in pathogens plus camel milk groups were pre-administered by camel milk for 2 weeks prior to pathogens injection. All animals were kept under observation for 8 days.

After the end of experimental schedule, all rats were decapitated after overnight fasting after diethyl ether inhalation. Blood was taken for serum extraction and organs were under aseptic conditions were used for pathogens isolation. Parts of liver, kidney, lung and intestine tissues were taken, weighted and checked for bacterial isolation (CFU/gram tissues for $S$. aureus and $E$. coli).

\subsection{Serum Extraction}

Blood was collected from eye using capillary tube inserted in retro-orbital venous plexuses. Blood was left to clot on air then in refrigerator for 30 minutes and centrifuged for 20 minutes at $4^{\circ} \mathrm{C}$. Supernatant serum was taken and stored at $-20^{\circ} \mathrm{C}$ till used for lysozyme and biochemical measurements.

\subsection{Plasma Chemistry Analysis}

Liver, kidney function tests and antioxidant parameters were measured using commercial kits that based on spectrophotometric analysis. All kits were purchased from Biodiagnostic Co, Dokki, Egypt.

\subsection{Lysoplate Assay}

Lyophilized micrococcus lysodeikticus $0.5 \mathrm{mg}$ per ml was suspended in $66 \mathrm{mM}$ sodium phosphate buffer $\left(\mathrm{Na}_{2} \mathrm{HPO}_{4}-\mathrm{NaH}_{2} \mathrm{PO}_{4}, \mathrm{pH} 7.0\right)$, combined with $1 \%$ agarose in $66 \mathrm{mM}$ sodium phosphate, and poured in petri dish. Evenly spaced 3-mm wells were punched in the solidified agar, and $60 \mu \mathrm{l}$ of sample was introduced into each well. The lysozyme enzymatic activity was determined by measuring the diameters of the zones of clearance relative to lysozyme standards [17]. 


\subsection{Statistical Analysis}

Results are expressed as means \pm S.E. for 5 independent rats per each group. Statistical analysis was done using ANOVA and Fischer's post hoc test, with $\mathrm{p}<$ 0.05 being considered as statistically significant.

\section{Results}

\subsection{In Vitro Synergistic Action of Camel Milk and Antibiotics}

The antibacterial activity of camel milk was assayed in vitro by agar well diffusion method against $E$. coli and $S$. aureus. Table 1 summarizes the maximum synergistic antibacterial activity of camel milk and ciprofloxacin (50 $\mathrm{mm}, 25 \mathrm{~mm}$ respectively) more than ciprofloxacin only (40 mm, $20 \mathrm{~mm}$ respectively).

Table 1. A. In vitro antimicrobial activity of camel milk

\begin{tabular}{|c|c|c|}
\hline \multirow{2}{*}{ E. coli } & Camel milk and Ciprofloxacin & Ciprofloxacin \\
\cline { 2 - 3 } S. aureus & 50 & 40 \\
\hline
\end{tabular}

Table (1 B). Culture of camel milk with or without ciprofloxacin together with $S$. aureus and $E$. coli

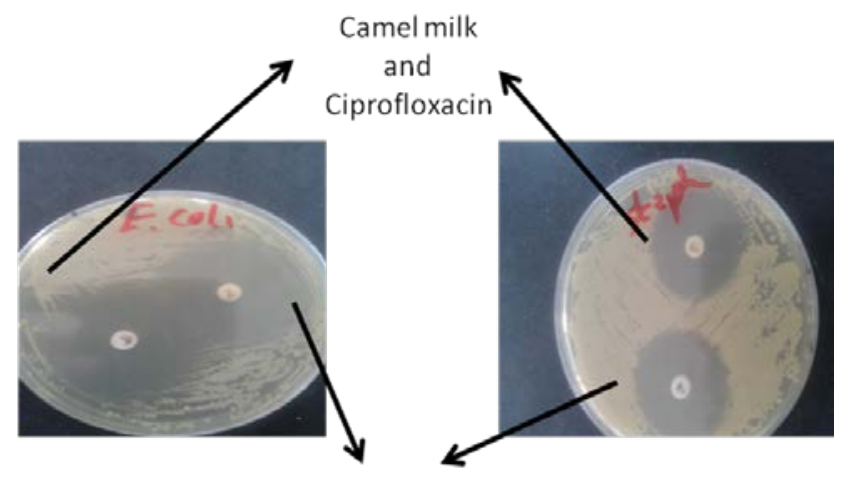

Ciprofloxacin

\subsection{Effect of Camel Milk on Total S. aureus Count in Different Organs of Wistar rats After Challenge}

The results in Table 2 showed that the total isolation rate of $S$. aureus in pathogen inoculated rats (S. aureus) are $349.5 \times 10^{5} \mathrm{CFU} / \mathrm{Gram}$ and was higher than in camel supplemented rats and injected $S$. aureus (71.6×10 $\mathrm{CFU} / \mathrm{gram})$. The isolation rate of $S$. aureus in $S$. aureus injected rats was higher in intestine $\left(247 \times 10^{5}\right.$ CFU/gram) followed by lung, kidney and liver respectively $\left(78 \times 10^{5}, 17.5 \times 10^{5}\right.$ and $7 \times 10^{5}$ respectively) as seen in Table 2. Prior camel supplementation decreased significantly the increase in $S$. aurus counts reported in $S$. aurus injected rats alone.

Table 2. Effect of camel milk on total $S$. aureus count in different organs of Wistar rat after $S$. aureus challenge

\begin{tabular}{|c|c|c|c|}
\hline & \multicolumn{3}{|c|}{ Mean of Total bacterial counts /gram tissue } \\
\hline & $\begin{array}{l}\text { S. aureus } \\
\text { injected } \\
\text { rats }\end{array}$ & $\begin{array}{c}\text { Camel milk } \\
\text { supplemented and } \\
\text { S. aureus injected } \\
\text { rats }\end{array}$ & $\begin{array}{l}\text { \% of decrease in } S \text {. } \\
\text { aureus pathogenicity } \\
\text { after camel milk } \\
\text { supplementation }\end{array}$ \\
\hline Kidney & $17.5 \times 10^{5}$ & $7 \times 10^{5} \mathrm{C}^{*}$ & $60 \%$ \\
\hline Lung & $78 \times 10^{5}$ & $14 \times 10^{5 *}$ & $82 \%$ \\
\hline Liver & $7 \times 10^{5}$ & $3.6 \times 10^{5 *}$ & $48.6 \%$ \\
\hline Intestine & $247 \times 10^{5}$ & $47 \times 10^{5 *}$ & $80 \%$ \\
\hline Total & $349.5 \times 10^{5}$ & $71.6 \times 10^{5 *}$ & $79.6 \%$ \\
\hline
\end{tabular}

Values are means \pm standard error (SEM) for 6 rats per each treatment.

Values are statistically significant at ${ }^{*} \mathrm{p}<0.05$ Vs. either S. aureus or E. coli group.

\subsection{Effect of Camel Milk on Total Bacterial Count of $E$. coli in Different Organs of Wistar Rats after Challenge}

The results in Table 3 showed that the total isolation rate of $E$. coli in $E$. coli injected rats was $153.5 \times 10^{5}$ CFU/gram and was higher than in camel milk supplemented plus E. coli injected rats $\left(100.9 \times 10^{5}\right.$ CFU/gram). The number of isolation rate of $E$. coli was higher in intestine $115 \times 10^{5} \mathrm{CFU} /$ gram followed by lung, kidney and liver respectively $\left(23 \times 10^{5}, 11 \times 10^{5}\right.$ and $4.5 \times 10^{5}$ respectively). Prior camel supplementation decreased significantly the increase in E. coli count reported in $E$. coli injected rats alone.

Table 3. Effect of camel milk on total bacterial count of $E$. coli in different organs of Wistar rats after challenge

\begin{tabular}{|c|c|c|c|}
\hline & \multicolumn{3}{|c|}{ Mean of Total bacterial counts /gram tissue } \\
\hline & $\begin{array}{l}\text { E. coli } \\
\text { injected } \\
\text { rats }\end{array}$ & $\begin{array}{c}\text { Camel milk } \\
\text { supplemented and } \\
\text { E. coli injected } \\
\text { rats }\end{array}$ & $\begin{array}{c}\% \text { of decrease in E. coli } \\
\text { pathogenicity after } \\
\text { camel milk } \\
\text { supplementation }\end{array}$ \\
\hline Kidney & $11 \times 10^{5}$ & $8.5 \times 10^{5 *}$ & $22.7 \%$ \\
\hline Lung & $23 \times 10^{5}$ & $19 \times 10^{5 *}$ & $17.4 \%$ \\
\hline Liver & $4.5 \times 10^{5}$ & $3.4 \times 10^{5 *}$ & $24.4 \%$ \\
\hline Intestine & $115 \times 10^{5}$ & $70 \times 10^{5 *}$ & $39.1 \%$ \\
\hline Total & $153.5 \times 10^{5}$ & $100.9 \times 10^{5 *}$ & $34.2 \%$ \\
\hline
\end{tabular}

Values are means \pm standard error (SEM) for 6 rats per each treatment. Values are statistically significant at $* \mathrm{p}<0.05$ Vs. either S. aureus or E. coli group.

\subsection{Lysozymes Assay}

The results in Table 4 show significant increase in lysozyme activities in E. coli injected rats compared to control and camel milk supplemented rats. Prior camel supplementation to E. coli injected rats showed additive stimulatory effect (1.86) compared to E. coli injected rats $(1.8 \mathrm{~cm})$. $S$. aureus alone or prior camel milk supplementation failed to induce any lysozyme activities compared to control and camel milk supplemented rats $(1.5 \mathrm{~cm})$.

Table 4. Lysozyme activity of camel milk in normal and pathogens injected rats

\begin{tabular}{|c|c|c|c|c|c|c|}
\hline & Control & Camel Milk & S. aureus. & S. aureus + Camel Milk & E. coil & E.coli +Milk \\
\hline Lysozyme inhibition zone (cm) & (1.5)a & (1.5)a & (1.66)a & (1.66)a & (1.8)b & $(1.86) \mathrm{b}$ \\
\hline
\end{tabular}

Values with same letters are insignificant and with different letters are significant at $\mathrm{p}<0.05$.

3.5. Effect of Camel Milk on Renal and Hepatic Alterations induced by $E$. coli and $S$. aureus in Wistar Rats
As seen in Table 5, injection of $E$.coli and $S$. aureus induced an increase in serum levels of kidney and hepatic biomarkers that represented by creatinine, urea, GPT and GOT. Prior camel milk supplementation normalized such 
Table 5. Changes in renal and hepatic biomarkers after $E$. coli and $S$. aureus injection in rats and protection by prior camel milk supplementation

\begin{tabular}{|c|c|c|c|c|c|c|}
\hline & Control & Camel Milk & E. Coli & CM + E. coli & S. aureus & S. aureus + CM \\
\hline Creatinine (mg/dL) & $0.99 \pm 0.004$ & $0.83 \pm 0.07$ & $1.87 \pm 0.03^{*}$ & $1.03 \pm 0.06 \#$ & $1.7 \pm 0.17 \ddagger$ & $0.86 \pm 0.04 \dagger$ \\
\hline Urea (mg/dL) & $44.3 \pm 8.6$ & $36.7 \pm 2.3$ & $139.7 \pm 3.9 *$ & $53 \pm 3.5 \#$ & $154 \pm 4.3 \ddagger$ & $46 \pm 1.2 \dagger$ \\
\hline GPT (U/L) & $78 \pm 8.6$ & $63.3 \pm 4.4$ & $174 \pm 9.5^{*}$ & $98.3 \pm 10.7 \#$ & $151.7 \pm 6.35 \ddagger$ & $77 \pm 8 \dagger$ \\
\hline GOT (U/L) & $62 \pm 7.2$ & $64 \pm 4.9$ & $145 \pm 5.5^{*}$ & $84.3 \pm 2.9 \#$ & $153 \pm 9.3 \neq$ & $76 \pm 12.5 \dagger$ \\
\hline
\end{tabular}

Values are means \pm standard error (SEM) for 6 rats per each treatment. Values are statistically significant at *p $<0.05$ Vs. control and camel milk, \#p $<$ 0.05 Vs. E. coli group and ${ }^{\dagger} \mathrm{p}<0.05$ Vs. S. aureus group. GPT = Glutamate pyruvate transaminase, GOT = Glutamate oxalate transaminase.

\subsection{Effect of Camel Milk on Antioxidant Levels and Alterations Induced by $E$. coli and S. aureus in Wistar Rats}

As seen in Table 6, injections of injection of E. coli and S. aureus intraperitoneally induced a decrease in serum levels of catalase, superoxide dismutase (SOD) and glutathione reductase (GR-ase) respectively. Pathogens injections induced state of oxidative stress that is indicated by the decrease in antioxidant levels. Of interest camel milk supplementation normalized catalase, SOD and GRase levels. These findings confirmed that camel milk has antioxidant activity during disease.

Table 6. Changes in antioxidant biomarkers after $E$.coli and $S$. aureus injection in rats and protection by prior camel milk supplementation

\begin{tabular}{|c|c|c|c|c|c|c|}
\hline & Control & camel milk & E. Coli & camel milk + E. Coli & S. aureus & camel milk + S. aureus \\
\hline SOD (U/L) & $16.7 \pm 2.4$ & $16 \pm 2.3$ & $11.3 \pm 0.5^{*}$ & $17.9 \pm 1.9 \#$ & $11.5 \pm 1.2^{*}$ & $17.7 \pm 2.99^{\dagger}$ \\
\hline Catalase (U/L) & $18.2 \pm 2.3$ & $18.9 \pm 2.5$ & $11.8 \pm 2.1^{*}$ & $17.6 \pm 1.39 \#$ & $12.1 \pm 2.8^{*}$ & $18.3 \pm 1.79^{\dagger}$ \\
\hline Glutathione reductase (U/L) & $12.3 \pm 2.1$ & $11.8 \pm 1.6$ & $6.1 \pm 1.9^{*}$ & $12.1 \pm 0.39 \#$ & $7.05 \pm 1.4^{*}$ & \\
\hline
\end{tabular}

Values are means \pm standard error (SEM) for 6 rats per each treatment. Values are statistically significant at *p $<0.05$ Vs. control and camel milk, \#p $<$ 0.05 Vs. E. coli group and ${ }^{\dagger} \mathrm{p}<0.05$ Vs. S. aureus group.

\section{Discussion}

The widespread usage of antibiotics has led to the increased environmental presence of pathogens; these pathogens are less susceptible to the antibacterial effect. Such resistance resulted in infections that are more difficult to cure. The efficacy of conventional antibiotic treatments against pathogens such as $S$. aureus is low [18]. Penicillin and closely related antibiotics of the $\beta$-lactam family are the best weapons against staphylococci. However, the massive usage of these antibiotics has led to a dramatic increase in pathogens that can produce an enzyme called $\beta$-lactamase that inactivates $\beta$-lactam antibiotics, thereby resulting in microbial resistance [19]. Therefore, there is an urgent need to find new antimicrobials to treat bacterial pathogens. It is generally well established that the food constituents can be used to reduce the risk of developing or aggravating human disease conditions. In this regard, functional foods and nutraceuticals have emerged as adjuvant or alternative to chemotherapy especially in the prevention and management of human diseases and for maintaining optimum health state [20]. Interest in camel milk usage for human nutrition is increasing due to its distinct composition and unique biofunctional properties [21].

Our results indicated that camel milk have synergistic action with antibiotic ciprofloxacin. These findings are in agreement with that of Diarra et al, [22], which may reduce the dose of antibiotics and decrease the bacterial resistance and that is good for human health and safety. Camel milk decreased the total bacterial count of $S$. aureus and E. coli in all tissues of rats in camel milk together with pathogen injected rats compared to pathogens alone injected rats. The possible explanation of such decrease may be attributed to high amounts of antimicrobial peptides such as Lysozyme (LZ), lactoferrin (LF), lactoperoxidase (LP), short peptidoglycan recognition protein (PGRP) present in camel milk $[23,24,25]$.
Lysozyme is one of the most ubiquitous antibacterial molecules that exert broad spectrum antimicrobial action. It has muramidase activity against Gram positive bacteria and Streptococcus [26,27]. In this study, the inhibition zone of $S$. aureus compared to control group have no significant effect. These results are in harmony to that reported by Viswanathan et al., [28] where S. aureus is resistant to hen egg white lysozyme (HEWL) and human lysozyme due to the O-acetylated at $\mathrm{C} 6-\mathrm{OH}$ in the muramic acid of peptidoglycan [29].

Enteric Gram-negative bacteria are protected from the external environment by their complex outer membrane structure [30]. Lysozyme is also active against some Gram-negative bacteria; however, because peptidoglycan is less abundant and less accessible in Gram-negative organisms, it is not clear if the muramidase activity and/or a non-enzymic bacteriolytic activity is responsible for this property [31]. It has been reported that HEWL acts against Gram negative bacteria by mechanisms such as perturbation of DNA or RNA synthesis and membrane permeabilization or disruption and this is the major mechanism by which antibacterial peptides and proteins act on both Gram negative and Gram positive bacteria [32].

Lactoferrin represents one of the first defense systems against microbial agents invading the organism mostly via mucosal tissues. Lactoferrin affects the growth and proliferation of a variety of infectious agents including both Gram-positive and Gram- negative bacteria, viruses, protozoa, or fungi. Its ability to bind free iron which is one of the elements essential for the growth of bacteria, is responsible for the bacteriostatic effect of lactoferrin [33]. Receptors for the N-terminal region of lactoferrin have been discovered on the surface of some microorganisms. The binding of lactoferrin to these receptors induces celldeath in Gram-negative bacteria due to disruption in the cell wall and subsequent release of lipopolysacharide (LPS) which leads to impair in permeability and a higher sensitivity to lysozyme and other antimicrobial agents [34,35]. Bactericidal activity affecting Gram-positive bac- 
teria is mediated by electrostatic interactions between the negatively charged lipid layer and the positively charged lactoferrin surface that cause changes in the permeability of the membrane [36].

Lactoperoxidase is found in milk, tears and saliva. It contributes to the non-immune host defensive system, exerting bactericidal activity, mainly on gram-negative bacteria. It is supposed that the main function in milk is the protection of the udder from microbial infections [37]. Moreover, lactoperoxidase was reported to have a general growth-promotion, anti-tumour activity and functional role in degradation of catecholamines [38,39].

It has been reported that unpasteurized camel milk is an excellent nutrient and because of its specific properties, particularly its anti-infectious action, should be used to replace other milks [40]. Based on these facts, we used unpasteurized camel milk and we didn't use cow milk because it already reported to be with little antimicrobial effects [40]. Moreover, heating didn't cause any alterations in antibacterial activity of camel milk [41], but we can't exclude the probability to destruct camel milk nanoparticles contents and inactivate its biological function especially in treatment of diabetes [41].

Alterations in serum levels of hepatic transaminases reported after pathogens injection indicate liver damage and necrosis [42]. Like ours, many studies reported malfunctioning of the liver transaminases due to the intracellular accumulation of lipids and microvesicular steatosis [43]. During inflammation, increased hepatic transaminases escape to the plasma from the injured hepatic cells. Therefore, the increment of the activities of hepatic transaminases in serum may be mainly due to leakage of these enzymes from the liver cytosol into blood stream [44]. This leakage causes a decrease in levels of GOT and GPT in hepatic cells but increase in their serum levels [45].

High levels of reactive oxygen species (ROS) is associated with cellular and mitochondrial damage and causes inflammation leading to tissue damage [46]. Pathogens and commensal bacteria generate free radicals and may cause inflammation and sepsis. Antioxidant defense systems consisting of antioxidant enzymes such as catalase), SOD, glutathione peroxidase and glutathione reductase (GR-ase) protect tissues from oxidative damage [47].

The hallmark of sepsis is a dysregulated and overwhelming inflammatory response, characterized by massive cytokine release, oxidative stress, and mitochondrial dysfunction in all organs affected. During sepsis, antioxidant defences are overwhelmed, and ROS cause cellular damage, contributing to organ dysfunction $[48,49]$. Antioxidants acting specifically in mitochondria might be beneficial in combating the inflammation and oxidative stress seen in sepsis [50,51,52]. Alteration in oxidative stress induced by reactive oxygen species (ROS) and impairments of the antioxidant system play a critical role in the pathogenesis of E.coli and S.aureus challenge $[53,54]$. As known, liver is the vital organ essential for the maintenance of systemic lipid homeostasis and metabolism, and easily susceptible to damage by ROS [55]. It has been shown that hyperlipidemia reduces the hepatic antioxidant defense system [56]. In the present study, camel milk supplementation decreased the oxidative stress biomarker malondialdehyde, and decreased the activity of antioxidant enzymes (catalase, SOD, and glutathione reductase) that were ameliorated by E. coli and S. aureus injection and challenge.

\section{Conclusion}

Current study clarify that camel milk has antibacterial effect against pathogenicity induced by $E$. coli and $S$. aureus in Wistar rats. Moreover, camel milk has synergistic action with antibiotics which may be used to reduce the dose of antibiotics and decrease bacterial antibiotic resistance. Camel milk supplementation decreased the oxidative stress and normalized antioxidants biomarkers that were ameliorated by $E$. coli and S. aureus injection.

\section{Acknowledgement}

This study was supported by a grant in aid of The Deans of Scientific Affairs, Taif University, Kingdom of Saudi Arabia (Research Project Number 3281-1-1435).

\section{Conflict of Interest}

The authors have declared that there is no conflict of interest.

\section{List of Abbreviations}

Phosphate Buffer Saline, PBS; Colony Forming Unites, CFU; Glutathione reductase, GR-ase; Hene Egg White Lysozyme, HEWL; Intraperitoneally, IP; Lactoferrin, LF; Lactoperoxidase, LP; Lipopolysaccharide, LPS; Lysozyme, LZ; Peptideglycan Recognition Protein, PGRP; Reactive Oxygen Species, ROS; Superoxide Dismutase, SOD.

\section{References}

[1] El-Agamy, S.I., Ruppanner. R. and Ismail, A, "Antibacterial and antiviral activity of camel milk protective proteins". Journal of Dairy Research., 59:169-175 . 1992.

[2] Agrawal, R.P., Dogra, R., Mohta, N., Tiwari, R., Singhal, S. and Sultania, S, "Beneficial effect of camel milk in diabetic nephropathy". Acta Biomedica., 80:131-134. 2009

[3] EL-Fakharany, E.M., Nawal, A., Bakry, M.H., Lourdes, S., Nezar, A.R. and Elrashdy, M.R," Anti-infectivity of camel polyclonal antibodies against hepatitis C virus in Huh7.5 hepatoma," Virology Journal., 201: 1-9. 2012.

[4] De Valdez, G.F., Bibi, W. and Bachmann, M.R," Antimicrobial effect of the lactoperoxydase/thiocyanate/hydrogen peroxide (LP) system on the activity of thermophilic starter culture. Milchwissenschaft., 43: 350-352. 1988.

[5] Kappeler, S.R., Ackermann, M., Farah, Z. and Puhan, Z,"Sequence analysis of camel (Camelus dromedarius) lactoferrin," International Dairy Journal, 82 (9): 481-448. 1999.

[6] Yagil, R," Camel milk-a review," International Journal of Animal Science, 2: 81-99. 1987.

[7] Korhonen, H., Pihlanto, A," Food-derived bioactive peptides opportunities for designing future foods," Current Pharmaceutical Design 9: 1297-1308. 2001.

[8] Omar, R.H., Eltinay, A.H," Microbial quality of camel's raw milk in central southern region of united Arab Emirates," Emir J Food Agric., 20 (1): 76-83. 2008. 
[9] Kappeler, S.R., Heuberger, C., Farah, Z. and Puhan, Z," Expression of the peptidoglycan recognition protein, PGRP, in the lactating mammary gland," Journal of Dairy Science, 87: 26602668. 2004.

[10] Velioglu Ogünç, A., Manukyan, M., Cingi, A., Eksioglu-Demiralp, E., Ozdemir, A. A. and Süha, Y. A," Dietary whey supplementation in experimental models of wound healing," International Journal for Vitamin and Nutrition Research, 78 (2): 70-73. 2008.

[11] Cimolai, N," MRSA and the environment: implications for comprehensive control measures," European Journal of Clinical Microbiology \& Infectious Diseases, 27 (7): 481-493. 2008.

[12] Welinder-Olsson, C., Kaijser, B," Enterohemorrhagic Escherichia coli (EHEC)," Scandinavian Journal of Infectious Diseases, 37 (67): 405-416. 2005.

[13] Cheesbrough, M," Medical Laboratory Manual for Tropical Countries," Microbiology, Linacre House, Jordan Hill Oxford p. 260. 2000.

[14] Althnaian, T., Albokhadaim, I. and El-Bahr S.M," Biochemical and histopathological study in rats intoxicated with carbontetrachloride and treated with camel milk," Springer Plus, 2 (1): 57. 2013.

[15] Cirioni, O., Giacometti, A., Ghiselli, R., Bergnach, C., Orlando, F., Silvestri, C., Mocchegiani, F., Licci, A., Skerlavaj, B., Rocchi, M., Saba, V. and Zanetti M," Scalise GLL-37 protects rats against lethal sepsis caused by gram-negative bacteria," Antimicrobial Agents Chemotherapy, 50 (5): 1672-1679. 2006.

[16] Hari Prasad, O., Navya, A., Vasu, D. and Chiranjeevi, T," Protective effects of Prosopis juliflora against Staphylococcus aureus induced hepatotoxicity in rats," International Journal of Pharmacy \& Biomedical Research, 2 (3): 172-178. 2011.

[17] Osserman, E.F., Lawlor, D.P," 1966. Serum and urinary lysozyme (muramidase) in monocytic and monomyelocytic leukemia. $J$ Exp Med 124: 921-952.

[18] Wilson, P., Andrews, J.A., Charlesworth, R., Walesby, R., Singer, M., Farrell, D.J. and Robbins, M," Linezolid resistance in clinical isolates of Staphylococcus aureus," The Journal of Antimicrobial Chemotherapy, 51: 186-188. 2003.

[19] Aarestrup, F.M., Jensen, N.E," Development of penicillin resistance among Staphylococcus aureus isolated from bovine mastitis in Denmark and other countries," Microbial \& Drug Resistance, 4: 247-256. 1998.

[20] Kris-Etherton, P. M., Hecker, K.D., Bonanome, A., Coval, S.M., Binkoski, A.E," Hilpert, K.F., Griel, A.E. and Etherton, T.D," Bioactive compounds in foods: their role in the prevention of cardiovascular disease and cancer," American Journal of Medicine, 113: 71-88. 2002.

[21] Sboui, A., Khorchani, T., Agrebi, A., Djegham, M., Mokni, M. and Belhadj, O," Antidiabetic effect of camel milk on alloxaninduced diabetic dogs. Afr J Microbiol Res., 6: 4023-4029. 2012.

[22] Diarra, M.S., Peticlerc, D. and Lacasse, P," Effect of lactoferrin in combination with penicillin on the morphology and the physiology of Staphylococcus aureus isolated from bovine mastitis," Journal of Dairy sciences, 85 (5): 1141-1149. 2002.

[23] El-Agamy, E.I., Ruppanner, R., Ismail, A., Champagne, C.P. and Assaf, R," Purification and characterization of lactoferrin, lactoperoxidase, lysozyme and immunoglobulins from camel's milk," International Dairy Journal, 6: 129-145. 1996.

[24] Benkerroum, N., Mekkaoui, M., Bennani, N. and Hidane, K," Antimicrobial activity of camel's milk against pathogenic strains of Escherichia coli and Listeria monocytogenes," International Journal Dairy Technology, 57:39-43. 2008.

[25] Abbas, S., Hifsa, A., Aalia, N. and Lubna, S," Physico-chemical analysis and composition of camel milk," International Research, 2 (2): 85-98. 2013.

[26] Mwambete, K.D," The in vitro antimicrobial activity of fruit and leaf crude extracts of Momordica charantia: a Tanzania medicinal plant," African Health Science, 9 (1): 34-39. 2009.

[27] Narmadha, G., Muneswararao, K., Rajesh, A. and Yenugu, S," Characterization of a novel lysozyme-like 4 gene in the rat," PLoS ONE, 6 (11): E27659-E27659. 2011.

[28] Viswanathan, K., Thomas, A., Dharmaraj, R., Narayanasamy, M. and Rangarajan, B.N," Assessment of antimicrobial activity of ctype lysozyme from Indian shrimp Fenneropenaeus Indicus," Journal of Coastal Life Medicine, 2 (10): 757-761. 2014.

[29] Shimada, T., Park, B.G., Wolf, A.J., Brikos, C., Goodridge, H.S. and Becker, C.A," Staphylococcus aureus evades lysozyme-based peptidoglycan digestion that links phagocytosis, inflammasome activation, and IL-1 $\beta$ secretion," Cell Host Microbe., 7 (1): 38-49. 2010.

[30] Nikaido, H., Vaara, M," Molecular basis of bacterial outer membrane permeability," Microbiol Rev., 49:1-32. 1985.

[31] Ibrahim, H.R., Matsuzaki, T. and Aoki, T," Genetic evidence that antibacterial activity of lysozyme is independent of its catalytic function," FEBS Letters, 506: 27-32. 2001.

[32] Zdybicka-Barabas, A., Stączek, S., Mak, P., Skrzypiec, K., Mendyk, E., Cytryńska, M," Synergistic action of Galleria mellonella apolipophorin III and lysozyme against Gram-negative bacteria. Biochim Biophys Acta, 1828 (6): 1449-1456. 2013.

[33] Arnold, R.R., Brewer, M. and Gauthier, J.J," Bactericidal activity of human lactoferrin: sensitivity of a variety of microorganisms," Infection and Immunity, 28: 893-898. 1980.

[34] Leitch, E.C., Willcox, M.D," Synergic anti-staphylococcal properties of lactoferrin and lysozyme," Journal of Medical Microbiology, 47: 837-842. 1998.

[35] Rossi, P., Giansanti, F., Boffi, A., Ajello, M., Valenti, P., Chiancone, E. and Antonini, G," $\mathrm{Ca}^{2+}$ binding to bovine lactoferrin enhances protein stability and influences the release of bacterial lipopolysaccharide," Biochemistry and Cell Biology, 80: 41-48. 2002.

[36] Valenti, P., Antonini, G," Lactoferrin: an important host defense against microbial and viral attack," Cellular and Molecular Life Sciences, 62: 2576-2587. 2005.

[37] Melda, S., Ekrem, K., Murat, C., Hasan, O., Ilhami, G. and Ali A," The prohibitive effect of lactoperoxidase system (LPS) on some pathogen fungi and bacteria," African Journal of Pharmacy and Pharmacology, 4: (9) 671-677. 2010.

[38] Andersson, L.A., Bylkas, S.A. and Wilson, A.E," Spectral analysis of lactoperoxidase. Evidence for a common heme in mammalian peroxidases," Journal of Biological Chemistry, 271: 3406-3412. 1996.

[39] Ueda, T., Sakamaki, K., Kuroki, T., Yano, I. and Nagata, S," Molecular cloning and characterization of the chromosomal gene for human lactoperoxidase," Eurapian Journal of Biochemistry, 243: 32-41. 1997.

[40] Cardoso, R.R., Ponte, M. and Leite V, " Protective action of camel milk in mice inoculated with Salmonella enterica." Isr. Med. Assoc. J., 15 (1): 5-8. 2013.

[41] Elagamy, E. I, " Effect of heat treatment on camel milk proteins with respect to antimicrobial factors: a comparison with cows' and buffalo milk proteins." Food Chemistry, 68: 227-232. 2000.

[42] Elagamy, E.I., Thapa, B.R., Walia, A," Liver function tests and their interpretation," Indian Journal of Pediatrics, 74: 663-671. 2007.

[43] Dixon, J.B., Bhathal, P.S., Brien, P. E," Nonalcoholic Fatty Liver Disease: Predictors of Nonalcoholic Steatohepatitis and Liver Fibrosis in the Severely Obese," Gastroenterology, 121 (1): 91100. 2001.

[44] El-Demerdash, F.M., Yousef, M.I. and Zoheir, M.A," 2005 Stannous chloride induces alterations in enzyme activities, lipid peroxidation and histopathology in male rabbit: antioxidant role of vitamin C," Food and Chemical Toxicology, 43 (12): 1743-1752.

[45] Yadav, N.P., Dixit, V.K," 2003. Hepatoprotective activity of leaves of Kalanchoe pinnata Pers," Journal of Ethnopharmacology, 86 (2-3): 197-202.

[46] Roberts, R.A., Smith, R.A., Safe, S., Szabo, C., Tjalkens, R.B. and Robertson, F.M," Toxicological and pathophysiological roles of reactive oxygen and nitrogen species. Toxicology, 276: 85-94. 2010.

[47] Pandey, S., Singh, A., Kumar, P., Chaudhari, A. and Nareshkumar, G," Probiotic Escherichia coli CFR 16 producing pyrroloquinoline quinone (PQQ) ameliorates 1,2-dimethylhydrazine-induced oxidative damage in colon and liver of rats," Appl Biochem Biotechnol 173 (3) 775-786. 2014.

[48] Exline, M.C., Crouser, E.D," Mitochondrial mechanisms of sepsis induced organ failure," Frontiers in Bioscience, 13: 5030-5041. 2008.

[49] Ruggieri, A.J., Levy, R.J. and Deutschman, C.S," 2010. Mitochondrial dysfunction and resuscitation in sepsis," Crit. Care Clin., 26: 567-575.

[50] Halliwell, B," Lipid peroxidation, antioxidants and cardiovascular disease: how should e move forward? Cardiovascular Research, 47:410-418. 2000.

[51] Victor, V.M., Espulgues, J.V., Hernandez-Mijares, A. and Rocha, M," Oxidative stress and mitochondrial dysfunction in sepsis: a 
potential therapy with mitochondria-targeted antioxidants," Infectious Disorders Drug Targets, 9: 376-89. 2009.

[52] Galley H.F," Oxidative stress and mitochondrial dysfunction in sepsis," Britsh Journal of Anaesthesia, 107: 57-64. 2011.

[53] Duarte, M.M., Rocha, J.B., Moresco, R.N., Duarte, T., Da Cruz, I.B., Loro, V.L. and Schetinger, M.R," Association between ischemia-modified albumin, lipids and inflammation biomarkers in patients with hypercholesterolemia," Clinical Biochemistry, 42 (7-8): 666-671. 2009.

[54] Hopps, E., Noto, D., Caimi, G. and Averna, M.R," A novel component of the metabolic syndrome: the oxidative stress. Nutr. Metab. Cardiovasc. Dis., 20: 72-77. 2010.
[55] Hamelet, J., Demluth, K., Paul, J.L., Delabar, J.M. and Janel, N," Hyperhomo-cysteinemia due to cystathionine beta synthase deficiency induces dysregulation of genes involved in hepatic lipid homeostasis in mice. Journal of Hepatolology, 46 (1): 151-159. 2007.

[56] Kumar, S.A., Sudhahar, V. and Varalakshmi, P," Protective role of eicosapentaenoate-lipoate (EPA-LA) derivative in combating oxidative hepatocellular injury in hypercholesterolemic atherogenesis. Atherosclerosis, 2006189 (1): 115-122. 2006. 